\title{
PRÁTICAS DE GESTÃO ESTRATÉGICA EM COMPANHIAS DE DANÇA DO BRASIL: ENTRE A ARTE E A INDÚSTRIA CULTURAL
}

\section{STRATEGIC MANAGEMENT PRACTICES IN BRAZILIAN DANCE COMPANIES: BETWEEN ART AND CULTURAL INDUSTRY}

\section{PRÁCTICAS DE GESTIÓN ESTRATÉGICA EN COMPAÑÍAS DE DANZA DE BRASIL: ENTRE LA ARTE E LA INDUSTRIA CULTURAL}

\section{Doris Dornelles de Almeida}

Mestre em Administração e Negócios pela Pontifícia Universidade Católica do Rio Grande do Sul PUC/RS

Pesquisadora do Red Antropología del Cuerpo, Argentina

E-mail: dornelles333@hotmail.com (Brasil)

\section{Peter Bent Hansen}

Doutor em Engenharia de Produção pela Universidade Federal do Rio Grande do Sul - UFRGS Professor da Pontifícia Universidade Católica do Rio Grande do Sul - PUC/RS

E-mail: peter.hansen@pucrs.br (Brasil) 


\title{
PRÁTICAS DE GESTÃO ESTRATÉGICA EM COMPANHIAS DE DANÇA DO BRASIL: ENTRE A ARTE E A INDÚSTRIA CULTURAL
}

\section{RESUMO}

Este artigo retrata teórica e empiricamente as principais práticas de gestão estratégica utilizadas em companhias de dança, visando sua sobrevivência, no atual contexto brasileiro. $O$ embasamento teórico aprofunda as temáticas do patrocínio, planejamento estratégico, criação e implementação de estratégias criativas e sustentabilidade econômica em companhias de dança. A pesquisa empírica envolve metodologia qualitativa, de caráter exploratório e a realização de entrevistas com sete gestores de Companhias de Dança brasileiras de Goiânia (1), Rio Grande do Sul (3), Paraná (1), Rio de Janeiro (1) e São Paulo (1). As análises das principais práticas de gestão estratégica dessas companhias de dança envolvem: pouca prática e considerável valorização do planejamento de gestão estratégica; resistência à aplicação de técnicas de gestão; influência limitada do público e dos patrocinadores na gestão destas companhias; dificuldade de gestão perante as políticas da indústria cultural. Este estudo contribui para o desenvolvimento do estado da arte das investigações na ciência da Administração e na área das artes, mais especificamente no segmento de Dança.

Palavras-chave: Companhias de Dança; Administração Estratégica; Sustentabilidade Econômica; Patrocínio; Indústria Cultural.

\section{STRATEGIC MANAGEMENT PRACTICES IN BRAZILIAN DANCE COMPANIES: BETWEEN ART AND CULTURAL INDUSTRY}

\begin{abstract}
This paper highlights trough theoretical and empirical research the main practices of dance companies' strategic management in Brazil. The theoretical investigation deepens themes as sponsorship, strategic planning, creation and implementation of creative strategies and economic sustainability in dance companies. The empirical research evolves qualitative method, exploratory and interviews with seven Brazilian dance companies managers from: Goiânia (1), Rio Grande do Sul (3), Paraná (1), Rio de Janeiro (1) e São Paulo (1). The analysis of the main practices of dance companies' strategic management is: few practice and considerable concern about strategic management planning; resistance to apply management techniques enforcement; audience and sponsors should have limited influence in dance companies' management; difficulty to accept itself inside the competitive cultural industry market. This study contributes for the development and state of art of Management science and Dance studies.
\end{abstract}

Keywords: Dance Companies; Strategic Management; Economic Sustainability; Sponsorship; Cultural Industry. 


\section{PRÁCTICAS DE GESTIÓN ESTRATÉGICA EN COMPAÑíAS DE DANZA DE BRASIL: ENTRE LA ARTE E LA INDUSTRIA CULTURAL}

\section{RESUMEN}

Este artículo retrata teórica y empíricamente las principales prácticas de gestión estratégica utilizadas en compañías de danza dentro del actual contexto brasileño. La base teórica profundiza las temáticas de auspiciantes, planificación estratégica, incubación e implementación de estrategias creativas y sustentabilidad económica en compañías de danza. La investigación empírica involucra metodología cualitativa, de carácter exploratorio y entrevistas con siete gestores de Compañías de Danza brasileñas de Goiânia (1), Rio Grande do Sul (3), Paraná (1), Rio de Janeiro (1) e São Paulo (1). Los análisis de las principales prácticas de gestión estratégica de aquellas compañías envuelven: poca práctica y considerable valorización de la planificación de gestión estratégica; resistencia a la aplicación de técnicas de gestión; el público y los auspiciantes deben poseer una influencia limitada en la gestión de las compañías de danza; y dificultad de percepción del mercado competitivo de la industria cultural. El siguiente estudio contribuye para el desarrollo de las investigaciones de la ciencia de la Administración y en el área de las Artes, especialmente en lo segmento de la Danza.

Palabras-claves: Compañías de Danza; Administración Estratégica; Sustentabilidad Económica; Auspiciantes; Industria Cultural. 
Práticas de Gestão Estratégica em Companhias de Dança do Brasil: entre a Arte e a Indústria Cultural

\section{INTRODUÇÃO}

Esta pesquisa visa mapear as principais características das práticas de gestão estratégica de companhias de dança brasileiras visando sua sobrevivência. O delineamento destas práticas oportuniza a reflexão sobre as estratégias de sustentabilidade e manutenção econômicas utilizadas por estas companhias, especialmente sobre o 'fazer artístico' e as relações da gestão aplicada por tais organizações artísticas com o público e patrocinadores. Daí surge a questão de pesquisa a ser respondida: quais as principais práticas de gestão estratégica utilizadas pelas companhias de dança brasileiras na busca de sua sobrevivência financeira?

A relevância do tema pesquisado reside na escassa produção teórica e empírica atual dos estudos da indústria cultural na ciência da Administração (O’Hagan \& Harvey, 2000; Kavanagh, O’Brien \& Linnane, 2002; Wilson \& Stokes, 2002; Fahy, Farrelly \& Quester, 2004; Frank \& Geppert, 2004; Kotler, 2005; Wood, Kirchbaum \& Cunha, 2009; Souza \& Carrieri, 2011) e na maior necessidade de estudos que entrelacem a área de Administração e de Dança (Legum \& George, 1981; Huntington, 2007; Dornelles de Almeida \& Flores-Pereira, 2013).

As companhias de dança em sua maioria dependem de patrocínio ou de ações filantrópicas para se sustentarem financeiramente, pois o valor dos ingressos dos espetáculos não cobrem seus custos fixos e variáveis. Tal fato dificulta sua independência, inclusive implicando inclusive na intervenção dos próprios patrocinadores nos conteúdos dos espetáculos apresentados (Legum \& George, 1981; O’Hagan \& Harvey, 2000; Dimaggio \& Powell, 2005; Huntington, 2007).

A configuração de formas de gestão de companhias de dança, por exemplo, é estruturalmente diferente daquela dos Estados Unidos (O’Hagan \& Harvey, 2000) e na Alemanha (Huntington, 2007). Para compreendê-las o presente artigo revisa inicialmente a gestão das companhias de dança em função: (i) do patrocínio; (ii) das suas aspirações artísticas e a adequação estratégica da administração junto ao público destas companhias; (iii) da influência do público na programação e no planejamento destas; (iv) do monitoramento e da captação de público deste tipo de organização artística.

A partir dessas premissas, considerou-se interessante verificar a existência de pontos convergências entre o material teórico pesquisado em outras regiões e países e confrontá-los com dados empíricos da realidade brasileira. Para tal, realizou-se uma pesquisa qualitativa de caráter exploratório em companhias de dança brasileiras sobre as suas práticas de gestão estratégica. Desta forma foi possível identificar as estratégias mais utilizadas e as menos consideradas atualmente na gestão destas companhias, analisar a sustentabilidade destas no longo prazo e a sua relação com o

Revista Ibero-Americana de Estratégia - RIAE, São Paulo, v. 12, n. 3, p. 125-150, jul./set. 2013. 
público financiador e consumidor. $\mathrm{O}$ artigo encontra-se estruturado nas seguintes seções: (i) revisão teórica com quatro subseções sobre as práticas estratégicas de gestão em companhias de dança; (ii) procedimento metodológico; (iii) caracterização das companhias de dança brasileiras pesquisadas; (iv) análise e reflexões sobre as práticas identificadas; (v) considerações finais sobre as contribuições deste trabalho, limitações e sugestões para pesquisas futuras.

\section{ESTRATÉGIAS DE GESTÃO NA INDÚSTRIA CULTURAL: SUSTENTABILIDADE DE COMPANHIAS DE DANÇA}

A problemática do patrocínio e da filantropia encontra-se presente na literatura sobre gestão de companhias de dança em vários países, denotando as preocupações de diversos pesquisadores com este tema (Legum \& George, 1981; O’Hagan \& Harvey, 2000; Fahy, Farrelly \& Quester, 2004; Frank \& Geppert, 2004; Dimaggio \& Powell, 2005; Hillyerhead, 2005; Kotler, 2005; Huntington, 2007). Estas pesquisas abordam visões convergentes sobre as ações estratégicas em companhias de dança, salientando as motivações e implicações do patrocínio como práticas de sustentabilidade financeira e os benefícios intrínsecos ao patrocinador como, por exemplo, a amplitude da imagem da empresa e da sua marca no mercado. No entanto estas pesquisas não elaboram uma contextualização das questões centrais, que envolvem o fazer artístico e a indústria do entretenimento. Fazer artístico entende-se pelos princípios que regem o processo de produção de uma obra artística, sem objetivar lucros financeiros, sendo diferentes em sua epistemologia da concepção da indústria do entretenimento, ligada diretamente á indústria cultural, com fins lucrativos, reprodução e mercantilização de obras de arte (Adorno, 1975).

Nas subseções seguintes são abordados tópicos relacionados a esta temática, como a influência da estrutura das organizações de artes no seu grau de sustentabilidade, a indústria cultural e a disseminação da arte como produto, a influência do público e do patrocinador na arte, as aspirações artísticas e a gestão estratégica das companhias de dança.

\subsection{A INFLUÊNCIA ESTRUTURAL DAS ORGANIZAÇÕES DE ARTES NO SEU GRAU DE SUSTENTABILIDADE}

As companhias de dança profissionais, de uma forma geral, estruturam-se de diferentes formas: (i) companhias de dança públicas em teatros públicos; (ii) companhias semiprivadas e privadas em teatros privados, (iii) artistas autônomos, entre outras formas. O mecanismo de 
Práticas de Gestão Estratégica em Companhias de Dança do Brasil: entre a Arte e a Indústria Cultural

burocratização e racionalização encontra-se presente tanto nas companhias de dança estruturadas em teatros públicos como nas privadas, ou ainda nas relações sociais profissionais entre artistas autônomos e patrocinadores (Dimaggio \& Powell, 2005). Para estes autores, o sistema de sustentabilidade financeira na administração de organizações sem fins lucrativos, como teatros geridos por diretores artísticos ou produtores executivos, baseia-se no patrocínio, doações e fundos do governo, de corporações ou fundações. "As políticas e estruturas das organizações artísticas tendem à centralidade da gestão com o propósito de promoção das carreiras dos gestores, principalmente nas organizações artísticas públicas onde o fluxo de pessoal é estruturado pela existência de títulos e trilhas de carreiras comuns, com significados usualmente compartilhados" (Dimaggio \& Powell, 2005, p.81).

A eficiência e a produtividade na gestão das organizações de artes são indicadores de difícil avaliação. Portanto estes gestores costumam basear suas tomadas de decisão em razões políticas mais do que em econômicas. Por exemplo, "no Metropolitan Opera de Nova Iorque, EUA, os patrocinadores preocupam-se mais com valores não econômicos, como qualidade, estética ou status social, do que com a eficiência da gestão do teatro em si” (Dimaggio \& Powell, 2005, p.85).

Este sistema de administração denota que a produção das artes depende da gestão estratégica de suas finanças, através de filantropia ou patrocínio, como forma de garantir a sustentabilidade econômica das atividades. A incerteza do ambiente dos negócios neste setor dá-se tanto em pequenas quanto em grandes corporações, sendo que as pequenas são mais suscetíveis à vulnerabilidade, especialmente quanto à questão financeira. Neste contexto, mostra-se difícil a análise de interação simples entre os agentes do setor artístico, onde o próprio criador pode também ser o produtor e consumidor de arte (Wilson \& Stokes, 2002). Neste contexto torna-se importante discutir a existência da indústria cultural e sua relação com a disseminação das obras de arte como produto.

\subsection{A INDÚSTRIA CULTURAL E A DISSEMINAÇÃO DA ARTE COMO PRODUTO}

Entre os séculos XIX e XX, Walter Benjamin e Theodor Adorno (Adorno, 1975) refletiram sobre as políticas de reprodução em massa de obras artísticas bem como as consequências futuras de sua massificação e padronização. Além da padronização, outra crítica fundamental destes autores sobre esta situação era a intenção de endereçar a obra de arte às massas no século XIX, construindo um caráter coletivo da reação maciça do público e não oportunizando as reações individuais quanto à fruição da obra contemplada.

Revista Ibero-Americana de Estratégia - RIAE, São Paulo, v. 12, n. 3, p. 125-150, jul./set. 2013. 
Estas reflexões culminariam no que Adorno (1975) nomeou de indústria cultural. Conforme Costa, Palheta, Mendes e Loureiro (2003) a indústria cultural foca no acúmulo de audiência. Adorno (1975) conceitua indústria cultural como produção cultural e simultaneamente comercial, que não subtrai a sua subjetividade mas que produz nos termos de audiência o consumo de objetos culturais (Costa et al., 2003). Segundo Kavanagh, O’Brien e Linnane (2002) uma contribuição teórica relevante de Adorno, considerava que o lazer e a arte vem sendo submetidos as mesmas tecnologias de racionalização e representação que já transformaram, no passado, a produção artesanal em produção em massa. Do ponto de vista de Adorno (1975), a dominação por meios instrumentais é persuasiva, sutil e uma perigosa ideologia que permeia não só a vida organizacional na forma de 'discurso administrativo', mas também penetra nas origens do entretenimento, lazer e arte (Kavanagh et al., 2002).

Neste contexto, uma das principais características da profissão dos bailarinos é o fazer arte por amor à arte; a profissão se torna uma vocação que transcende o negócio, o trabalho, gerando uma satisfação intrínseca da própria atividade através de um senso de reconhecimento público (Roncaglia, 2008). Isto pode ser positivo pelo lado de criatividade e espaço para novas idéias, e negativo quando a sociedade assume que esta profissão não é séria e digna de reconhecimento (Wilson \& Stokes, 2002).

Por sua vez, Bourdieu (1988) define o campo artístico como autônomo devido aos critérios que regem as relações entre os indivíduos dentro deste. Desta forma, este autor considera que estes agentes (bailarinos, artistas) possuem estratégias de diferenciação em relação a outros campos de atividades socioeconômicas. Deve ser lembrado que o campo para Bourdieu (1988) é estruturado por dimensões culturais, políticas, sociais e simbólicas.

Nesta linha de análise, o debate dá-se sobre os fatos que geram inclusão ou exclusão de determinados públicos e maior ou menor apoio financeiro a determinados tipos de artes (Frank \& Geppert, 2004; Huntington, 2007). Para Wilson e Stokes (2002) existe necessidade da adoção de estratégias de promoção pública pelos empreendedores culturais, devido ao problema de comunicação entre a indústria cultural e os provedores financeiros. Esta ação, segundo estes autores, minimizaria as relações de conflitos políticos que se criam entre estes gestores culturais e da indústria cultural, os quais 'não falam a mesma linguagem'. Esta falta de entendimento reflete-se principalmente na falta de harmonia de interesses entre administradores-proprietários, investidores e patrocinadores. Os gestores financeiros de organizações comerciais indicam a necessidade das organizações de artes utilizarem mecanismos de infraestrutura financeira (projeção de investimento de mercado, previsão e controle de custos e investimentos, prospecção de recursos). Estes autores

Revista Ibero-Americana de Estratégia - RIAE, São Paulo, v. 12, n. 3, p. 93125-150, jul./set. 2013. 
Práticas de Gestão Estratégica em Companhias de Dança do Brasil: entre a Arte e a Indústria Cultural

expõem que a indústria das artes é administrada por pessoas que não demonstram senso e clareza em gestão (como negociação, visão holística do negócio) especialmente financeira, denotando a falta de capacidades efetivas de comunicação alicerçadas no conhecimento da administração, finanças e experiência no ramo (Wilson \& Stokes, 2002). Este campo de rivalidade e competição da indústria cultural (Adorno, 1975) indica uma separação de cultura; de um lado as corporações e de outro os artistas, constituindo agentes com interesses e valores de culturas diversas participando do mesmo setor das atividades de artes.

Neste contexto, a incerteza do ambiente cultural faz com que os empreendedores culturais (normalmente artistas) necessitem conciliar as virtudes de independência com as qualidades apropriadas de parceria e estratégias de promoção, capacidades de comunicação efetiva e autossuficiência financeira, na busca de otimização das condições de intercâmbio do empreendedorismo cultural. Tal conciliação "demanda capacidade de combinar o entendimento e experiência das relações de administração de finanças, com especialistas habilitados em conhecimento especializado nas artes" (Wilson \& Stokes, 2002, p.51, tradução dos autores).

Por outro lado, o patrocínio constitui-se na principal fonte de sustentabilidade financeira das organizações artísticas, inclusive das companhias de dança. Algumas instituições pequenas são observadas sistematicamente por patrocinadores para seleção e aplicação de investimentos de patrocínio, com intuito de retorno através da propaganda sobre a imagem da empresa e ações altruístas (Frank \& Geppert, 2004).

Para O’Hagan e Harvey (2000) e Frank e Geppert (2004) o patrocínio de artes funciona como uma ferramenta de promoção e propaganda, sendo seus efeitos proporcionalmente dependentes do número de visitantes (assistentes). Isto facilita o recebimento de doações por instituições maiores, tornando-as mais conhecidas pelos patrocinadores e, consequentemente, obtendo maior possibilidade de cobertura de mídia, atraindo maior atenção do público e facilitando as decisões de patrocínio. A arrecadação de fundos por parte das organizações artísticas necessita de fontes administrativas competentes, pois o custo (de oportunidade) é independente do tamanho da audiência.

\subsection{A INFLUÊNCIA do PÚBlico / PATROCINAdOR NA ARTE E NAS PRÁtiCAS ESTRATÉGICAS}

Em 1980 as investigações sobre o modus operandi de companhias de dança, demonstrava o receio destas na aplicação de estratégias de adequação dos programas de dança aos desejos do

Revista Ibero-Americana de Estratégia - RIAE, São Paulo, v. 12, n. 3, p. 125-150, jul./set. 2013. 
consumidor, devido à crença de que a administração sobrepor-se-ia ao 'fazer a arte per se' (Legum \& George, 1981).

Nesta linha, Oetinger (2004, p.18) reflete sobre este dilema afirmando: "escute seus clientes, mas não faça tudo que eles dizem", baseado em frustrações dos relatos de produtores artísticos que atenderam as demandas de mercado. O diretor da Broadway Hal

Prince (Oetinger, 2004) confessou frustração com a falta de imaginação demonstrada pelas audiências de teatros contemporâneos, as quais diminuíram suas aspirações com o passar dos anos por dizerem querer obras repetitivas, as quais não valem à pena serem feitas. De acordo com o diretor a audiência necessita de algo com frescor, em resposta às suas necessidades. Ou seja, segundo ele a audiência não quer experimentar, não quer fazer uma leitura da narrativa e completar as entrelinhas, usar a imaginação e sim quer ver uma história sem espaço para descobrimento. O público não tendo acesso a diversas alternativas, não tem como avaliá-las e um artista que 'pensa', pode usar novas ideias para transformar a realidade (Oetinger, 2004).

O reconhecimento pelo mercado de algumas companhias de dança em detrimento de outras, ocorre da sua própria propaganda e da receptividade do público. Estes fatores influenciam proporcionalmente na escolha do patrocinador ao avaliar tal organização. A propaganda anual de instituições culturais é avaliada pela visibilidade desta junto ao público. O montante de patrocínio recebido e o orçamento anual da instituição cultural podem ser determinados pela orientação de negócios da instituição, ou pelo senso de marketing e comunicação com os consumidores e patrocinadores. As decisões administrativas das instituições de artes impactam nas decisões dos patrocinadores e do público em apreciar espetáculos de dança. Os números de visitantes esperados são calculados em função do tamanho de audiências passadas, sendo fundamental esclarecer que as inovações artísticas ou tradições das instituições de artes, do 'fazer artístico', podem diferir dos interesses dos patrocinadores ou mesmo do público (Frank \& Geppert, 2004).

A principal meta dos patrocinadores de artes é a propaganda de seu estabelecimento, como uma ferramenta promocional (Legum \& George, 1981; O’Hagan \& Harvey, 2002; Frank \& Geppert, 2004; Kotler, 2005). Frank e Geppert (2004) descobriram doadores que visavam estratégias de retorno de investimento sobre o patrocínio, levando o foco para longe de princípios altruístas. Nestes estudos os doadores favorecem organizações de artes como operas, ballets e orquestras.

Nas últimas décadas Legum e George (1981), O’Hagan e Harvey (2002), Frank e Geppert (2004) e Kotler (2005), identificaram as principais motivações para o patrocínio artístico pelas empresas, como sendo: (i) promoção de sua imagem e nome; (ii) fortalecimento da sua cadeia de

Revista Ibero-Americana de Estratégia - RIAE, São Paulo, v. 12, n. 3, p. 93125-150, jul./set. 2013. 
Práticas de Gestão Estratégica em Companhias de Dança do Brasil: entre a Arte e a Indústria Cultural

suprimentos; (iii) oportunidade de procura de aluguel e benefícios não monetários para administradores e proprietários. Observa-se que existe uma parcela, ainda que pequena, de filantropia no patrocínio, especialmente em pequenas empresas, principalmente relacionada com o indivíduo em si e seu envolvimento e doação ao patrocinar as artes, retornando algo à sociedade. Estes estudos evidenciam o poder intrínseco do patrocínio, através dos benefícios, que estas ações possibilitam para as empresas. Deste modo, o patrocínio vai além do simples depósito de dinheiro doado às organizações de artes, existindo interesses e expectativas dos patrocinadores de retorno dos fundos de patrocínio investidos nas artes.

\subsection{ASPIRAÇÕES ARTíSTICAS E A GESTÃo ESTRATÉGICA DE COMPANHIAS DE DANÇA}

Legum e George (1981) identificaram um fator sobre o paradoxo descrito anteriormente na gestão de companhias de dança: o fato do uso de técnicas de marketing não serem utilizadas estrategicamente para o crescimento destas organizações de artes, deixando-as atuar diretamente em termos de liberdade artística e de criatividade na concepção do programa de dança a ser exibido. Este problema de gestão também é apresentado por Fahy et al. (2004), os quais associam o poder imperativo exercido pelo patrocinador sobre a companhia na concepção do programa, com o intuito de privilegiar a marca e imagem que a empresa patrocinadora deseja construir junto ao público, denotando uma relação hierarquicamente superior do patrocinador sobre a companhia de dança (já que a sustentabilidade financeira da última é estruturada principalmente em função do primeiro).

Visto que o patrocínio, as doações decorrentes de filantropia, unidas aos fundos governamentais e à venda de ingressos compõem a principal fonte de sustentabilidade financeira das organizações de artes, é pertinente analisar como ocorrem as práticas de gestão das companhias de dança nestes quesitos. A efetividade do marketing utilizado pelas empresas patrocinadoras nos eventos artísticos tende a estar relacionada à presença de recursos intangíveis, como habilidades para construção de marca e competências de patrocínio ao longo do tempo. Constitui-se o intuito de criar uma identificação do público com a empresa que proporcionou o evento artístico vivenciado (Fahy et al., 2004).

Embora as companhias de dança em sua maioria continuem dependentes financeiramente dos agentes sociais (recursos de patrocínio, doações e governo), isso não as libera da responsabilidade de disseminar sua própria imagem e desenvolver meios de comunicação eficientes com o público e os patrocinadores. Para isso, elas devem visar à autonomia de administração, 
sustentabilidade no longo prazo e redução da incerteza do ambiente e da dependência de agentes externos, utilizando estratégias de gestão como, por exemplo, marketing e finanças (Legum \& George, 1981).

Neste sentido é importante analisar a formulação das estratégias das organizações de artes, considerando as situações particulares e específicas destas. Dentro deste contexto, Kotler (2005) registrou a aplicação de estratégias de marketing em outras áreas, além das puramente comerciais, entre as quais: museus, artes cênicas, espetáculos, igrejas, agências sociais, governos de cidades, grupos de ação social e celebridades. Os benefícios da ampliação deste campo de estudo do marketing influenciaram estas áreas, nas quais gestores de atividades não puramente comerciais se beneficiaram destas técnicas no alcance de seus objetivos, através da análise de formas para atrair e servir visitantes, membros, doadores, clientes e outros grupos de stakeholders. Surgiram novas áreas desenvolvidas, segundo Kotler (2005), como: marketing social, marketing educacional, marketing da saúde, marketing da celebridade, marketing cultural (museus e artes cênicas), marketing para igrejas, e marketing de lugar. Estas aplicações de marketing trouxeram consigo ideias inovadoras sobre o relacionamento dos indivíduos consumidores na sociedade, oportunizando a administração sustentável destas organizações e um crescimento histórico destes setores. Conforme este mesmo autor a invasão do marketing na arena não-comercial, ao segmentar, focar esforços e posicionar estas organizações, oportunizou o entendimento de seu público de forma eficaz e permitiu o uso da comunicação e promoção da difusão de informações.

Segundo alguns estudiosos (Legum \& George, 1981; O’Hagan \& Harvey, 2002; Huntington, 2007) a utilização de estratégias nas companhias de dança são consideradas ineficientes ou inexistentes. Segundo Huntington (2007) são diversas as estratégias aplicadas à gestão de companhias de dança, variando de acordo com a cultura de cada país. Por exemplo, na Alemanha existem políticas públicas de inclusão social envolvendo as artes numa macro escala (Huntington, 2007). A crítica desta autora refere-se à aplicação de técnicas de gestão de marketing na área das artes, especificamente do conceito dos quatro P's (preço, produto, promoção e praça), típico das empresas comerciais. Para ela, a estratégia de marketing aplicada ao setor privado não se aplica às artes cênicas, às organizações sem fins lucrativos ou não comerciais, devido ao problema de aplicação de preço e intangibilidade do produto não serem claros nestas.

Huntington (2007) considera que a falha de promoção dos veículos de mídia dos espetáculos de dança ajuda a explicar a falta de repetição na compra, sem que mudanças de comportamento sejam evidenciadas devido à dificuldade de monitoramento deste processo Existe a necessidade das companhias de dança construírem um modelo de marketing desenhado unicamente para as artes

Revista Ibero-Americana de Estratégia - RIAE, São Paulo, v. 12, n. 3, p. 93125-150, jul./set. 2013. 
cênicas, que provoque o envolvimento do consumidor, o crescimento da audiência e a redução da exclusão de populações de baixa renda no acesso às artes (Huntington, 2007). Além disso, a existência de um sistema hierárquico e a dificuldade de comunicação entre os agentes envolvidos no processo de decisão estratégica nas organizações de artes, muitas vezes as desvirtua de seus propósitos artísticos iniciais em virtude de problemas de comunicação entre a sua administração e os artistas (Legum \& George, 1981).

\section{PROCEDIMENTOS METODOLÓGICOS}

Com o objetivo de identificar as práticas de gestão estratégicas em companhias de dança profissionais brasileiras, realizou-se uma pesquisa empírica de cunho qualitativo, a qual se refere a um "paradigma fenomenológico de suposição ontológica na qual a realidade é subjetiva e múltipla" (Collis \& Hussey, 2006, p.55). Buscou-se entender e explorar o contexto em estudo, conforme Sampieri, Collado e Lúcio (2006) e Denzin e Lincoln (2006). Deste modo, esta pesquisa é de caráter exploratório e de corte transversal, pois visa observar o fenômeno em um dado momento de sua história.

$\mathrm{Na}$ primeira etapa foram contatadas, durante um período de cinco meses, cinquenta companhias de dança. Estes endereços foram selecionados através do portal virtual do Ministério da Cultura do governo federal brasileiro, denominado FUNARTE (Fundação Nacional de Arte), de websites privados de dança como Idance.net, e sites das próprias companhias. Na tentativa de envolver o maior número possível de respondentes algumas destas companhias foram contatadas mais de cinco vezes, seguindo sugestão de Flick (2004). O requisito para participação na pesquisa era o cargo de diretor ou profissional envolvido na gestão da respectiva companhia. Informou-se às organizações o caráter voluntário e sigiloso da pesquisa e envio dos resultados obtidos aos participantes para sua anuência. Os respondentes foram sete gestores e ou responsáveis da produção das companhias de dança de: Goiânia (1), Rio Grande do Sul (3), Paraná (1), Rio de Janeiro (1) e São Paulo (1).

A elaboração dos roteiros de entrevista foi inspirada em estudos validados e aplicados por Legum e George em 1981 nos EUA sobre esta mesma temática, optando-se por verificar sua aplicabilidade no Brasil. Contudo, diferentemente dos questionários aplicados por Legum e George (1981), buscou-se deixar em aberto às perguntas para livre participação dos respondentes na pesquisa, oportunizando riqueza das respostas e liberdade de expressão. A aplicação dos roteiros de 
entrevista semiestruturados deu-se por correio eletrônico (e-mail) devido ao fato da maioria destas companhias estarem localizadas em diferentes estados do território nacional, fato que limitou parcialmente os questionamentos realizados.

Os dados foram coletados entre junho e novembro de 2010. A dificuldade significativa de se obter resposta de um número maior de gestores de companhias de dança denotou resistência no fornecimento de informações sobre suas estratégias de gestão. Este fato poderia ser considerado como limitação metodológica para a pesquisa, devido ao baixo grau de resposta obtido frente ao desejado. No entanto, a amostragem ofereceu certa relevância qualitativa (mas não quantitativa) devido ao aprofundamento das respostas (Flick, 2004) sobre o conhecimento das práticas estratégicas das companhias de dança brasileiras. Para isso foi realizada análise do conteúdo dos dados (primários) das entrevistas em conjunto com informações disponíveis (Bell, 2008) nos sites das próprias companhias de dança e outras fontes como jornais e revistas (dados secundários) em relação com a revisão teórica elaborada.

\section{CARACTERÍSTICAS DAS COMPANHIAS DE DANÇA BRASILEIRAS}

As sete companhias de dança profissionais pesquisadas existem em média há dezoito anos no mercado e somente uma delas exerce suas atividades desde 1927. Todas são consideradas de pequeno porte, com exceção da mais antiga que é de grande porte. O número de bailarinos empregados varia de sete a doze, e de administradores e técnicos contratados de três a treze pessoas, com exceção da organização de grande porte que possui oitenta e oito bailarinos (adicionados a cinco mestres de ballet, cinco ensaiadores, quatro pianistas e dez pessoas do staff artístico).

Os respondentes da pesquisa são diretores e coreógrafos destas companhias, sendo o maior tempo de experiência de um destes de vinte e dois anos. Todas as companhias de dança realizam tournées nacionais exceto uma, e três realizam tournées nacionais e internacionais. O montante de patrocínio anual recebido varia entre $\mathrm{R} \$ 38.000,00$ e $\mathrm{R} \$ 600.000,00$ (reais), sendo que a companhia de maior porte não especificou o montante recebido. O montante gasto com marketing anualmente varia entre $\mathrm{R} \$ 1.000,00$ e $\mathrm{R} \$ 100.000,00$. O público que vivencia os espetáculos oferecidos por estas companhias varia anualmente entre 200 e 32.000 pessoas, sendo que uma das companhias atrai 165.000 pessoas por ano.

O quadro 1 resume as informações coletadas sobre algumas variáveis relevantes para análise da gestão estratégica destas companhias de dança, com algarismos representando os nomes dos 
Práticas de Gestão Estratégica em Companhias de Dança do Brasil: entre a Arte e a Indústria Cultural

entrevistados e letras representando os nomes das respectivas companhias, respeitando o sigilo solicitado por estas organizações.

\begin{tabular}{|c|c|c|c|c|c|c|c|}
\hline $\begin{array}{l}\text { Estado/Cias de } \\
\text { Dança/ } \\
\text { Estrutura }\end{array}$ & $\begin{array}{l}\text { SP (A) } \\
\text { Privada }\end{array}$ & $\begin{array}{l}\text { RS (B) } \\
\text { Privada }\end{array}$ & $\begin{array}{l}\text { RS (C) } \\
\text { Privada }\end{array}$ & $\begin{array}{l}\text { GO } \\
\text { Privada }\end{array}$ & $\begin{array}{l}\text { PR (E ) } \\
\text { Privada }\end{array}$ & $\begin{array}{l}\text { RS (F) } \\
\text { Pública }\end{array}$ & $\begin{array}{l}\text { RJ (G) } \\
\text { Públic }\end{array}$ \\
\hline $\begin{array}{l}\text { Respondente/ } \\
\text { Tempo na Cia }\end{array}$ & $\begin{array}{c}1 \\
\text { Direção/ } \\
\text { 1 ano 8mês. }\end{array}$ & $\begin{array}{c}2 \\
\text { Direção/ } \\
15 \text { anos }\end{array}$ & $\begin{array}{c}3 \\
\text { Direção/ } \\
22 \text { anos }\end{array}$ & $\begin{array}{c}4 \\
\text { Produção }\end{array}$ & $\begin{array}{c}5 \\
\text { Direção } \\
17 \text { anos }\end{array}$ & $\begin{array}{c}6 \\
\text { Direção/ } \\
13 \text { anos }\end{array}$ & $\begin{array}{c}7 \\
\text { Pesquisa / } \\
\text { Não } \\
\text { informou }\end{array}$ \\
\hline $\begin{array}{c}\text { Tempo da } \\
\text { existência Cia }\end{array}$ & 15 anos & 15 anos & 22 anos & 22 anos & 17 anos & 13 anos & 83 \\
\hline Porte CiaDança & Pequena & Pequen & Pequen & Pequena & Pequena & Pequena & Grande \\
\hline No Bailarinos & 11 & 7 & 9 & 8 & 1 & 10 & \\
\hline $\begin{array}{c}\text { Administração } \\
\text { e Técnicos }\end{array}$ & 3 & 3 & 3 & 13 & $B$ & 6 & $88 \quad 30$ \\
\hline $\begin{array}{l}\text { Tournées } \\
\text { Nacionais }\end{array}$ & Sim & Não & $\begin{array}{l}\mathrm{Si} \\
\mathrm{m}\end{array}$ & Sim & Sim & Si m & $\begin{array}{l}\mathrm{Si} \\
\mathrm{m}\end{array}$ \\
\hline $\begin{array}{c}\text { Tournées } \\
\text { Internacionais }\end{array}$ & Sim & Não & Não & Sim & Sim & Não & Não \\
\hline $\begin{array}{c}\text { Montante } \\
\text { Patrocínio } \\
\text { Recebido/Ano }\end{array}$ & $\begin{array}{c}500.000,00 \\
\mathrm{R} \$\end{array}$ & $\begin{array}{l}38.000,0 \\
0 \quad \mathrm{R} \$\end{array}$ & $\begin{array}{c}60.000,00 \\
\mathrm{R} \$\end{array}$ & $\begin{array}{c}500.000,00 \\
\mathrm{R} \$\end{array}$ & $\begin{array}{l}600.000,0 \\
0 \quad \mathrm{R} \$\end{array}$ & $\begin{array}{l}100.000,00 \\
\mathrm{R} \$ \\
\text { Verba Munic. }\end{array}$ & $\begin{array}{l}\text { Verba } \\
\text { pública/Não } \\
\text { informou }\end{array}$ \\
\hline $\begin{array}{c}\text { Montante } \\
\text { dispêndio } \\
\text { Marketing/ano }\end{array}$ & $\begin{array}{c}20.000,00 \\
\mathrm{R} \$\end{array}$ & $\begin{array}{c}1.000,00 \\
\mathrm{R} \$\end{array}$ & $\begin{array}{c}20.000,00 \\
R \$\end{array}$ & $\begin{array}{c}100.000,00 \\
R \$\end{array}$ & $\begin{array}{c}50.000,00 \\
\mathrm{R} \$\end{array}$ & $\begin{array}{l}\text { 5.000,00 R\$ } \\
\text { + apoio setor } \\
\text { comunicação } \\
\text { Prefeitura } \\
\text { mídia espont. }\end{array}$ & $\begin{array}{c}\text { Verba } \\
\text { pública } \\
\text { Não } \\
\text { informou }\end{array}$ \\
\hline $\begin{array}{c}\text { \% de dispêndio } \\
\text { Marketing por } \\
\text { ano/Total de } \\
\text { patrocínio }\end{array}$ & $4 \%$ & $2,63 \%$ & $33 \%$ & $20 \%$ & $8,33 \%$ & $\begin{array}{c}\text { 8,33\% } \\
\text { (excluídos } \\
\text { gastos mídia } \\
\text { espontânea) }\end{array}$ & - \\
\hline $\begin{array}{l}\text { Monitoramento } \\
\text { da audiência } \\
\text { espetáculos/ano }\end{array}$ & $\begin{array}{l}30.000 \\
\text { pessoas }\end{array}$ & $\begin{array}{c}200 \\
\text { pessoas }\end{array}$ & $\begin{array}{l}20.000 \\
\text { pessoas }\end{array}$ & $\begin{array}{l}32.00 \\
\text { pessoas }\end{array}$ & $\begin{array}{l}20.000 \\
\text { pessoas }\end{array}$ & $\begin{array}{c}5.000 \\
\text { pessoas }\end{array}$ & $\begin{array}{l}165.000 \\
\text { pessoas }\end{array}$ \\
\hline
\end{tabular}

Quadro 1 - Dados gerais das companhias de dança brasileiras pesquisadas.

Fonte: Autores com base nas entrevistas realizadas na pesquisa.

\section{ANÁlise DAS PRÁticas de GESTÃo ESTRATÉGICA NAS COMPANHIAS DE DANÇA}

A forma de garantia da sustentabilidade financeira identificada nas respostas das sete companhias de dança consiste no patrocínio anual que varia entre $\mathrm{R} \$ 38.000,00$ e $\mathrm{R} \$ 600.000,00$ via projetos de Lei de Incentivo à Cultura (LIC) dos âmbitos federal, estadual, ou municipal.

Revista Ibero-Americana de Estratégia - RIAE, São Paulo, v. 12, n. 3, p. 125-150, jul./set. 2013. 
Somente uma companhia de dança $(\mathrm{G})$ não informou o montante de patrocínio recebido e afirmou que possui estratégias de captação de recursos através de recursos públicos via Lei Rouanet (lei federal de incentivo à cultura) e através de doações (mecenato) individuais a partir da associação dos amigos do teatro onde atua. Sendo que estas companhias apresentam um número de contratados variando de sete a doze bailarinos, exceto a companhia $\mathrm{G}$ que possui oitenta e oito bailarinos.

Duas das companhias de dança são públicas, com incentivo direto através da folha de pagamento do governo municipal (F) e estadual (G), e seus integrantes possuem plano de cargos e salários como funcionários públicos. As companhias são geridas em sua maioria pelos próprios coreógrafos ou diretores. Neste sentido, os achados reforçam a literatura de Dimaggio e Powell (2005) e Wilson e Stokes (2002) na identificação de que a administração destas organizações artísticas e sem fins lucrativos é realizada por diretores artísticos ou produtores executivos, mantendo-se sua sustentabilidade financeira a partir de patrocínio, doações e fundos do governo, de corporações ou fundações. Além disso, a companhia de dança $(\mathrm{G})$ afirma que o cargo de diretor é preenchido por indicação, ou seja, cargo de confiança da Presidência da Fundação do teatro, reforçando as premissas de Dimaggio e Powell (2005) de que as carreiras dos gestores em teatros públicos são preenchidas por razões políticas de acordo com o caráter de governança pública vigente.

Tratando-se agora das práticas estratégicas, verifica-se que o montante gasto por ano pelas companhias com marketing (exceto a companhia G que não informou), varia de $\mathrm{R} \$ 1.000,00$ a $\mathrm{R} \$$ 100.000,00. Considerando o montante de patrocínio recebido anualmente, os valores anteriores representam uma relação de $2,63 \%$ a $33 \%$ de gastos com marketing sobre o total de patrocínio recebido por ano. Como o marketing engloba ações referentes à promoção e propaganda, coleta de opiniões do público e monitoramento de sua frequência, estes dados representam um grau bastante diferenciado de reconhecimento da importância de informar o público sobre a companhia de dança, bem como de tornar-se conhecida pelos patrocinadores.

Estas práticas corroboram parcialmente as premissas de Frank e Geppert (2004) de que as organizações artísticas dependem de sua visibilidade junto ao público, de seu senso de marketing e comunicação com os consumidores e patrocinadores para sua sustentabilidade. Estas ações se comprovam nas falas dos respondentes sobre a dicotomia do uso de ações de marketing ao reconhecer sua importância e, ao mesmo tempo, não julgarem relevante que estas práticas sejam prioritárias sobre as necessidades artísticas. As companhias de dança reconhecem os desejos e necessidades do público, descrevendo ações realizadas, pelas afirmações dos respondentes como, por exemplo, (convenção: Empresa / Respondente):

Revista Ibero-Americana de Estratégia - RIAE, São Paulo, v. 12, n. 3, p. 93125-150, jul./set. 2013. 
A (1)-[...] os profissionais desta equipe, além de bailarinos, também desempenham um papel de artistas orientadores na comunidade por meio de um programa de oficinas permanentes nos Centros Culturais dos bairros da cidade. Isso nos aproxima da população, possibilitando que tenhamos melhor filtro daquilo que o público em geral aprecia em dança. Além disso, os resultados de nosso trabalho, a crítica dos espetáculos e o retorno da plateia são extremamente positivos.

C (3)- A arte somente se dá mediante a audiência, contanto sem renunciar à linguagem. A dança é um bem cultural, e por ser, é destinado ao consumo, o que é não o mesmo que o consumo popularmente concebido como a compra de um bem durável ou efêmero de retorno à curto, médio ou a longo prazos. Consumo, aqui, remete ao acesso a um bem imaterial que visa à transformação social, verificado na geração de capital humano e social, onde o econômico é o meio e não o fim.

\section{Contudo as companhias de dança esclarecem que as necessidades artísticas devem} prevalecer sobre os desejos e necessidades do público:

A (1)- Não é interessante a arte "entregar" ao público aquilo que ele sempre quer ver, já conhece ou está acostumado devido à cultura de massa, etc. Mas ao mesmo tempo, não me parece inteligente criar e apresentar espetáculos que satisfaçam apenas ao ego do próprio artista. Ou seja, obras que não comunicam a não ser aquele que a compôs, por exemplo. A arte precisa instigar, provocar e tudo isso com um bom olhar à estética e à poesia.

C (3)- Se enquanto "empresa" afinada com os desejos artísticos, o que é a nossa visão, isto exige uma constante atualização mediada por estudos da economia cultural. No caso da dança contemporânea que trabalha, entre outros, a pesquisa sistemática, a ousadia e o processo de experimentação, não se pode ter a medida do desejo do público como tarefa, pois assim, incorreríamos na banalização da arte. A dança contemporânea não se reserva ao momento da exibição, tampouco se resume ao sucesso. Sua tarefa é, justamente, a de quebrar paradigmas a de provocar reflexões explorando o senso incomum, ou seja, àquilo que não é dado pronto, como satisfazer o gosto do grande público.

E (5)-[...] temos que respeitar o público, porém não trabalhamos na direção de criar apenas o que agrada, há uma relação mais complexa onde os caminhos da Cia. são trilhados levando em consideração uma pesquisa e também tendo o público como foco, mas sem se render somente à lógica do mercado.

As companhias de dança convergem em suas opiniões de não realizarem diferentes tipos de programação para públicos diversos, tentando distanciar a caracterização dos espetáculos do produto de consumo, como afirmam:

C (3)-[...] públicos categorizados são aqueles, no meu entendimento, é trabalhado para consumir aquilo, que à priori, destinamos o produto de fácil assimilação para uns e para outros não. Importante ter claro, que os públicos são flutuantes, e à medida da oferta, eles se movem.

D (4)- Entre espetáculos, workshops, mostras de vídeo... talvez. Mas em termos de diferentes espetáculos, acreditamos que, como temos várias obras em cartaz, primamos por aproveitar o mercado levando para esta ou aquela cidade espetáculo que ainda não tenha sido apresentado na localidade. Portanto, primamos pelo ineditismo.

Revista Ibero-Americana de Estratégia - RIAE, São Paulo, v. 12, n. 3, p. 125-150, jul./set. 2013. 
E (5)- [...] não há como, um trabalho com identidade e singularidade, não tem como realizar projetos com foco neste ou naquele público, o público fará a escolha de acompanhar ou não o projeto.

Constata-se que as práticas de gestão destas companhias não corroboram as premissas de Kotler (2005) quanto à necessidade de desenvolvimento de técnicas específicas de gestão de marketing aplicáveis às companhias de dança, de modo a estabelecerem um relacionamento com o público que vise a sustentabilidade da organização ao longo do tempo.

No quadro 2 encontram-se as informações resumidas sobre a gestão estratégica das companhias de dança pesquisadas; as letras representam os nomes das companhias.

\begin{tabular}{|c|c|c|c|}
\hline \multirow{2}{*}{ QUESTÕES APRESENTADAS PARA AS CIAS. DE DANÇA } & \multicolumn{3}{|c|}{ Respostas das Cias. de Dança } \\
\hline & Discorda & Ás vezes & Concorda \\
\hline A Cia se define no ramo da indústria do entretenimento & C D E F G & & A B \\
\hline A Cia reconhece os desejos e necessidades do público & & & ABCDEFG \\
\hline A Cia deve dar prioridade aos desejos do público acima das necessidades artísticas & C D F G & A B E & \\
\hline $\begin{array}{l}\text { A Cia deve Segmentar seu público e direcionar seus esforços a cada segmento } \\
\text { separadamente }\end{array}$ & ABCDEFG & & \\
\hline A Cia deve oferecer diferentes tipos de programação para cada Segmento de mercado & $\mathrm{ABCEFG}$ & & $\mathrm{D}$ \\
\hline A Cia realiza promoção e propaganda direcionados a diferentes segmentos de mercado & ABDEFG & $\mathrm{C}$ & \\
\hline A Cia deve desenvolver unicidade objetivando competir com outras organizações & $\mathrm{ABCDFG}$ & $\mathrm{E}$ & \\
\hline A qualidade dos espetáculos é a maior determinante na venda de ingressos & B D F & $\mathrm{E}$ & $\mathrm{AC} \mathrm{G}$ \\
\hline O custo de presenciar um espetáculo envolve mais do que o preço dos ingressos & & $\mathrm{C}$ & ABDEFG \\
\hline A audiência deve ter maior influência na definição dos preços dos espetáculos & A & & BCDEFG \\
\hline $\begin{array}{l}\text { O planejamento da promoção deve iniciar pela análise do programa seguido de um } \\
\text { plano de como será vendido ao público em geral }\end{array}$ & & & ABCDEFG \\
\hline
\end{tabular}

Revista Ibero-Americana de Estratégia - RIAE, São Paulo, v. 12, n. 3, p. 93125-150, jul./set. 2013. 
Práticas de Gestão Estratégica em Companhias de Dança do Brasil: entre a Arte e a Indústria Cultural

\begin{tabular}{|c|c|c|c|}
\hline $\begin{array}{l}\text { Uma vez finalizada a campanha de promoção a Cia não necessita realizar mais } \\
\text { comunicações de marketing com o público }\end{array}$ & ABCDEFG & & \\
\hline A audiência tem influência sobre o local no qual os espetáculos da Cia devem ocorrer & & & ABCDEFG \\
\hline $\begin{array}{l}\text { É essencial que todo pessoal que lida com o público seja coordenado pelo mesmo } \\
\text { indivíduo }\end{array}$ & & & ABCDEF \\
\hline A Cia coordena e integra os contatos com o público através de seu pessoal & & & ABCDEF \\
\hline $\begin{array}{l}\text { Há necessidade de avaliação periódica sobre a opinião da audiência com relação ao } \\
\text { programa de espetáculos da Cia }\end{array}$ & B G & A & C D E F \\
\hline A Cia coleta regularmente informações das opiniões do público & B C G & A & D E F \\
\hline A Cia deve ser administrada pelas mesmas técnicas usadas em empresas comerciais & ABCDEFG & & \\
\hline Técnicas de marketing são muito comerciais para utilização em uma Cia de Dança & & & ABCDEFG \\
\hline
\end{tabular}

Quadro 2- Práticas de gestão estratégica voltadas à sustentabilidade de companhias de dança brasileiras. Fonte: Autores com base nas entrevistas realizadas.

\section{REFLEXões SOBRE AS PRÁticas DE GESTÃo ESTRATÉGiCA NAS COMPANHIAS DE DANÇA BRASILEIRAS}

Com intuito de melhor expressar uma reflexão das práticas de gestão das companhias pesquisadas esta seção está dividida em quatro subseções, sejam elas: (i) Companhia de Dança na Indústria Cultural e a Comercialização da Arte; (ii) Inclusão ou exclusão social: miopia da gestão estratégica das companhias de dança; (iii) Planejamento na Gestão das Companhias de Dança; (iv) Monitoramento do Público e Aplicação de Técnicas de Gestão ‘Comerciais'.

\subsection{A COMPANHIA DE DANÇA NA INDÚSTRIA CULTURAL E A COMERCIALIZAÇÃO DA ARTE}

Revista Ibero-Americana de Estratégia - RIAE, São Paulo, v. 12, n. 3, p. 125-150, jul./set. 2013. 
As companhias de dança alcançam sustentabilidade econômica no longo prazo através da venda de espetáculos e cursos de dança, sendo estas atividades principais o motor para suas práticas de gestão estratégica. Daí surge uma questão relevante a ser discutida: a comercialização da arte e a inserção na indústria cultural. Analisando as práticas estratégicas de gestão destas companhias de dança, seus gestores demonstraram reconhecer suas organizações como parte do mercado da indústria cultural. Como por exemplo, "a dança como outras linguagens artísticas além de informar, provocar a reflexão crítica, educar, também tem seu papel no ramo do entretenimento" (A, 1, entrevista), seguida do relato:

C (3)- A companhia, hoje, se adequa no ramo da indústria cultural (criativa), ainda que o termo seja muito criticado por alguns autores, já que remete à mercantilização e massificação da arte, rejeitando a relação da mesma com a economia, transformando assim, o artista em instrumento de consumo. É preciso rever as formas jurídicas para contemplar os movimentos sociais culturais e suas estratificações.

A preocupação constante destes gestores é concomitantemente encontrarem equilíbrio entre as políticas da indústria cultural e um modo particular de gestão que não atenda á mercantilização das obras artísticas. Estas afirmações, corroboram com as ideias de Wagner (1856 apud Berry, 2004), Benjamin e Adorno (1975), Kavanagh et al.(2002) e Wilson e Stokes (2002), de que a arte endereçada às massas na indústria cultural corrompe-se ao ser tratada de modo 'comercial' acompanhada do tratamento do público como 'consumidor cultural'.

Nesse sentido, os gestores pesquisados em sua maioria declararam que devem dar prioridade as necessidades artísticas da companhia, ou seja, buscar priorizar uma gestão para longe da mercantilização e assim não focar seus esforços exclusivamente nos desejos da plateia.

\subsection{INCLUSÃO OU EXCLUSÃO SOCIAL: MIOPIA DA GESTÃO ESTRATÉGICA NAS COMPANHIAS DE DANÇA}

Os debates trazidos por Huntington (2007) e Frank e Geppert (2004) sobre a segmentação de mercado em companhias de dança, como instrumento de estímulo à inclusão social, não condizem com as práticas de gestão estratégica das companhias de dança brasileiras pesquisadas, as quais, conforme os respondentes, não utilizam técnicas de segmentação de mercado para atingir o público de espetáculos de dança. As companhias de dança rejeitam, de forma quase unânime (seis das sete companhias), práticas de gestão que envolvam segmentar seu público e direcionar seus esforços a cada segmento separadamente. Ou seja, não oferecem diferentes tipos de programação direcionados a cada segmento de mercado e desenvolvendo senso de unicidade objetivando competir com outras

Revista Ibero-Americana de Estratégia - RIAE, São Paulo, v. 12, n. 3, p. 93125-150, jul./set. 2013. 
Práticas de Gestão Estratégica em Companhias de Dança do Brasil: entre a Arte e a Indústria Cultural

organizações culturais. No entanto, quase metade dos gestores das companhias pesquisadas (A,C,G) afirmam que a qualidade do espetáculo, ou seja, a riqueza da obra artística como um todo, a performance técnica e artística dos bailarinos na coreografia aliada á música, ao cenário e ao local do espetáculo, é determinante na venda de ingressos. Além disso, reconhecem que devem dar atenção aos desejos e necessidades do público, constituindo-se esta uma questão problemática entre a prática aplicada e idealizada na gestão destas companhias.

\subsection{O PLANEJAMENTO NA GESTÃO DAS COMPANHIAS DE DANÇA}

As companhias de dança pesquisadas não acreditam que o público deva influenciar a programação dos espetáculos, corroborando as premissas de Legum e George (1981) e Oetinger (2004). Segundo estes autores, este tipo de influência constitui-se em um problema da gestão artística em tentar atender as demandas de mercado, pois restringe o acesso do público à diversidade artística e à reflexão capaz de transformar a realidade associado ao fazer artístico. De modo que, quando se realiza somente o que a audiência deseja, ela torna-se alienada e desestimulada ao uso da imaginação, prejudicando o desenvolvimento intelectual deste público (Oetinger, 2004). Frank e Geppert (2004) refletem que o 'fazer artístico' pode diferir dos interesses dos patrocinadores ou do público. Neste sentido as premissas acima citadas corroboram a crítica do respondente sobre a influência do público na programação artística da Companhia:

B (2)- Pode ser uma medida complicada (deixar o público influenciar na programação dos espetáculos), à medida que se ficará à disposição do gosto da audiência, acarretando em certa falta de liberdade de ação.

Por outro lado, a maioria das companhias de dança acredita que a audiência deve ter maior influência na definição dos preços dos espetáculos, mesmo que algumas defendam o governo como principal responsável por estas práticas:

C (3)- Hoje, a cultura visa democratização. Neste sentido, os preços dos ingressos, como contrapartida, são populares. Considerando que a cultura, hoje, é um direito essencial incluído na Constituição Federal do Brasil, igual como morar, vestir, se alimentar, transportar e estudar, considero importante vincular os preços dos ingressos dos espetáculos ao acesso à cultura. Sou favorável a este acesso e considero que o preço popular possibilitará, aos poucos, que todos tenham este "direito" garantido, ao contrário de privilégio garantido. A formação de uma consciência sociocultural depende diretamente, da desconstrução dos modelos estereotipados de que o "preço" do ingresso equivale a "qualidade" do espetáculo. [...] Políticas públicas devem ser elaboradas para definição de preços de ingressos, mas tendo em vista tanto o público, quanto os custos do artista e dos produtores com o espetáculo.

Revista Ibero-Americana de Estratégia - RIAE, São Paulo, v. 12, n. 3, p. 125-150, jul./set. 2013. 
Além disso, as companhias de dança são unânimes quanto: (i) ao planejamento da promoção dos espetáculos, o qual deve se iniciar pela análise do programa e ser seguido de um plano de como será vendido ao público em geral; (ii) ao planejamento das temporadas, que necessitam de campanhas específicas para cada produção durante o ano com objetivo de captar o público; (iii) ao planejamento das campanhas de promoção, as quais devem prever comunicações de marketing constantes com o público; e, essencial, (iv) o planejamento coordenado pelo mesmo indivíduo (centralização e hierarquia na gestão) de todo pessoal que lida com o público. Estas ações corroboram as premissas de Dimaggio e Powell (2005) sobre centralização da gestão em teatros, as necessidades de adoção de estratégias de promoção de Wilson e Stokes (2002) e as estratégias de 'retorno' da imagem do marketing utilizadas por companhias de dança segundo O'Hagan e Harvey (2000).

As companhias de dança pesquisadas ainda reconhecem a influência da audiência no planejamento sobre o local onde os espetáculos devem ocorrer e onde os ingressos dos espetáculos devem ser vendidos pela companhia.

\subsection{MONITORAMENTO DO PÚBLICO E APLICAÇÃO DE TÉCNICAS DE GESTÃo 'COMERCIAIS'}

Quatro das companhias de dança pesquisadas $(\mathrm{C}, \mathrm{D}, \mathrm{E}, \mathrm{F})$ concordam quanto à necessidade de avaliação periódica da opinião da audiência com relação ao programa de espetáculos, e três destas realmente aplicam a coleta regular de informações das opiniões do público (D, E, F). No entanto, uma destas especifica suas práticas, corroborando as premissas de Kotler (2005) sobre a necessidade de implantação de monitoramento do público em eventos culturais. Como se percebe na fala do respondente:

E (5)- Sim. Fazemos isto sistematicamente há 17 anos. Não sabemos se podemos chamar de “comunicações de marketing”, mas em toda apresentação de espetáculo, o público recebe, juntamente com o programa do espetáculo, uma ficha de cadastro, onde além de deixar seu nome, endereço, profissão, cadastrando-se assim como "público do Ballet", a pessoa é convidada a dar sua opinião sobre nosso trabalho. Desta forma, como já dissemos, temos um mailing bastante extenso através do qual mantemos nosso público informado a respeito de nossas atividades.

Importante salientar á partir desse relato que os gestores das companhias de dança pesquisadas não consideraram comentar o uso das mídias sociais como recurso de comunicação 
com o público e divulgação dos espetáculos, embora todas estas companhias utilizem este recurso, seja através de websites próprios, seja através de redes de comunicação virtuais.

Por último, os gestores das companhias de dança foram unânimes quanto à rejeição de administração deste tipo de organização pelas mesmas técnicas de marketing usadas por empresas comerciais, como ressaltado nas falas dos respondentes:

A (1)- Deve-se utilizar de alguns recursos, que podem ser interessantes. Porém, o olhar artístico é diferente do comercial. Assim, numa Companhia, mesmo utilizando-se de algumas técnicas empresariais de marketing, o olhar artístico é o que fala por último.

C (3)- Depende. As técnicas de marketing da arte não se resumem aos princípios comerciais, mas também! As estratégias são similares, no entanto não são regidas pelo sistema de comercialização, se entendidas como "comércio", já que elas "escapam" ao sentido jurídico, que é essencialmente econômico. Necessariamente, estas técnicas têm tarefas que vão além do que a ciência da economia até então cunhou.

E (5)- Não conhecemos muito as técnicas de marketing. Entendemos que a busca da sustentabilidade financeira é imprescindível, mas nos parece natural que uma Companhia de Dança, como é o Ballet E, que é um projeto vinculado a uma Fundação Privada sem fins lucrativos de caráter cultural, não seja administrada com os mesmos princípios uma empresa comercial.

Á partir destas afirmações considera-se que os gestores das companhias pesquisadas consideram imprescindível a sua sustentabilidade financeira, no entanto encontram conflitos na aplicação de estratégias regidas por um sistema de comercialização. Estas práticas corroboram as premissas estratégicas dos atores no campo artístico teorizados por Bourdieu (1988), especialmente quanto à diferenciação construída em relação aos outros campos de atividades, objetivando manter um campo autônomo de atuação específico das companhias de dança perante a indústria cultural.

\section{CONSIDERAÇÕES FINAIS}

Esta pesquisa teórico empírica realizada em sete companhias de dança brasileiras apresenta como achados principais o delineamento das práticas de gestão estratégicas atuais dentro de um contexto sócio-histórico-social, permitindo um melhor entendimento por parte dos gestores, coreógrafos e diretores, sobre o seu papel e posição no mercado das organizações artísticas. Estas organizações se caracterizam pela manutenção de valores quanto ao 'fazer a arte per se', e possuem uma relação adversa junto às práticas consideradas 'muito comerciais' pertinentes as políticas da indústria do entretenimento. 
Neste sentido, as principais interpretações que esta pesquisa proporcionou sobre as práticas de gestão estratégicas aplicadas pelas companhias de dança brasileiras, convergentes com os achados na literatura, são: (i) estas não se definem pertencentes ao ramo da indústria do entretenimento; (ii) afirmam reconhecer os desejos e as necessidades do público, no entanto não os consideram na prática; (iii) não acreditam que devam dar prioridade aos desejos do público acima das necessidades artísticas; (iv) rejeitam as práticas de gestão que envolvam segmentar o público e direcionar seus esforços a cada segmento separadamente; (v) não consideram competir com outras organizações culturais; (vi) consideram que o público e patrocinadores devem possuir influência limitada na gestão das companhias de dança; (vii) apresentam tendência parcial ao monitoramento do público nos espetáculos; (viii) apresentam resistência à aplicação de técnicas comerciais de marketing; e (ix) apresentam considerações positivas quanto ao planejamento de gestão estratégica, mesmo que poucas o pratiquem de fato.

A partir disso, parece constituir uma necessidade o planejamento de longo prazo destas organizações, visto que, por exemplo, sem um monitoramento constante, manutenção e criação de relacionamento com seu público, estas organizações artísticas estarão submetidas a riscos quanto à continuidade de suas atividades, como afirma Oetinger (2004), principalmente na atual sociedade globalizada e informatizada.

Os resultados encontrados nesta pesquisa mostram à necessidade de se analisar em profundidade a questão da profissionalização da gestão de companhias de dança. Deste modo contribui-se para que os gestores identifiquem tanto pontos fracos da atual gestão das companhias, como também contradições sobre o conhecimento das demandas do mercado da indústria cultural, e seu julgamento de poder adequar-se as políticas deste mercado sem atender a uma mercantilização de suas obras artísticas.

Espera-se que este artigo sirva de subsídio para a elaboração de futuras pesquisas que possam ampliar o quadro de informações sobre este tema na área de gestão cultural, bem como propicie estímulo a futuros estudos sobre o aperfeiçoamento e desenvolvimento das práticas de gestão de companhias de dança. Ressaltamos que se por um lado quantidade de participantes desta pesquisa pudesse ser considerada como uma limitação, por outro, a riqueza de suas respostas serviu para o delineamento inicial de suas práticas de gestão estratégica, que podem ampliados em pesquisas futuras. Nesse sentido, sugere-se, por exemplo, realização de estudos longitudinais sobre a evolução de outros aspectos estratégicos praticados pelos gestores e análise de seus resultados em companhias de dança.

Revista Ibero-Americana de Estratégia - RIAE, São Paulo, v. 12, n. 3, p. 93125-150, jul./set. 2013. 
Práticas de Gestão Estratégica em Companhias de Dança do Brasil: entre a Arte e a Indústria Cultural

\section{REFERÊNCIAS}

Adorno, T.; Benjamin, W. (1975) A obra de arte na época de suas técnicas de reprodução. Textos Escolhidos. In Coleção Os Pensadores. São Paulo: Abril S.A Cultural e Industrial, pp.7-34.

Bell, J. (2008) Criando e Aplicando um Questionário. In Projeto de Pesquisa: guia para pesquisadores iniciantes em educação, saúde e ciências sociais. Porto Alegre: Artmed, pp. 119134.

Berry, M. (2004) Richard Wagner and the politics of Music Drama. The Historical Journal, 47(3), pp. 663-683.

Bourdieu, P. (1988) La distincion-Criterio y bases sociales del gusto. Ed. Taurus. Orig.1979/Traduccion Maria del Carmen Ruiz de Elvira. Espanha. 596 p.

Collis, J.; Hussey, R. (2005) Como lidar com questões conceituais. In: Pesquisa em Administração. 2. ed. Porto Alegre: Bookman. pp. 53-82.

Costa, A. M. S.; Palheta, A. N. A A.; Mendes, A M. P.; Loureiro, A. S. (2003) Indústria Cultural: revisando Adorno e Horkheimer. Movendo Ideias, Belém, 8(13), pp.13-22.

Denzin, N.; Lincoln, Y. S. (2006) Paradigmáticas, contradições, e confluências emergentes.In: $O$ Planejanento da Pesquisa Qualitativa; teorias e Abordagens. pp. 169-192.

Dimaggio, P. J.; Powell, W. W. (2005) A Gaiola de Ferro Revisitada: Isomorfismo Institucional e Racionalidade Coletiva nos Campos Organizacionais. RAE, 45(2), pp. 74-89.

Dornelles de Almeida, D.; Flores-Pereira, M.T. (2013) As Corporalidades do Trabalho Bailarino: entre a Exigência Extrema e o Dançar com a Alma. RAC, 17 (6) pp. 720-738

Fahy, J.; Farrelly, F.; Quester, P. (2004) Competitive advantage through sponsorship: A conceptual model and research propositons. European Journal of Marketing, 38(8), pp.1013-1030.

Flick, U. (2004) Estratégias de Amostragem. In: Introdução à Pesquisa Qualitativa. Porto Alegre: Bookman, pp.76-86.

Frank, B. F.; Geppert, K. (2004) Are small Recipients Overlooked by sponsors? An empirical Note. Journal of Cultural Economics, (28), pp.143-156.

FUNARTE

(2010).

Disponível

em:

<http://200.143.203.68/novafunarte/funarte/danca/listagem.php> Acesso: maio 2010.

Revista Ibero-Americana de Estratégia - RIAE, São Paulo, v. 12, n. 3, p. 125-150, jul./set. 2013. 
Hillyerhead, L. (2005) Disponível em: <http://www.vam.ac.uk/res_cons/conservation/journal/number_50/diaghilev/> Summer: Number 50, Working for Diaghilev. Acesso: abril 2010.

Huntington, C. S. (2007) Reevaluating segmentation practices and public policy in classical performing arts marketing: a macro approach. Journal of Arts Management, Law and Society, 37(2), pp.127-142.

Kavanagh, D.; O’Brien, C.; Linnane, M. (2002) Art, Work and Art Work. Creativity and Innovation Management. Blackwell Publishers, 11(4), pp.277-286.

Kotler, P. (2005) The role played by the broadening of marketing movement in the history of marketing thought. Journal of Public Policy \& Marketing, 24(1), Spring pp.114-116.

Legum, L. T.; George, W. R. (1981) Analysis of marketing management practices of dance companies. Academy of Marketing Science Journal, 9, 1/2, Winter/Spring pp.15-26.

O’Hagan, J.; Harvey, D. (2000) Why do companies sponsor Arts Events? Some Evidence and a proposed Classification. Journal of Cultural Economics, 24(3), pp.205-224.

Oetinger, B. V. (2004) Break your own rules. Emerald Group, Journal of Business Strategy, 25(6), pp.13-20.

Roncaglia, I. (2008) The ballet dancing profession: a career transition model. Australian Journal of Career Development, 17(1), pp. 50-59.

Sampieri, R. H.; Collado, C. F.; Lúcio, P. B. (2006) Formulação de Hipóteses In: Metodologia de Pesquisa. São Paulo: McGraw-Hill, pp. 116-151.

Souza, M.M.P.; Carrieri, A.P. (2011) Racionalidades no fazer artístico: estudando a perspectiva de um Grupo de Teatro. RAE São Paulo, 51(4), pp. 382-395.

Wilson, N.; Stokes, D. (2002) Cultural Entrepeneurs and Creating Exchange. Journal of Research in Marketing and Entrepeneurship, v (4) Issue 2, pp.37-52.

Wood, T.; Kirshbaum, C.; Cunha, M.P. (2009) Indústrias Criativas: definição, limites e possibilidades. RAE, São Paulo, 49(1), pp. 010-018.

Revista Ibero-Americana de Estratégia - RIAE, São Paulo, v. 12, n. 3, p. 93125-150, jul./set. 2013. 
Práticas de Gestão Estratégica em Companhias de Dança do Brasil: entre a Arte e a Indústria Cultural

Recebido: 29/05/2013

Aprovado: 13/07/2013

Revista Ibero-Americana de Estratégia - RIAE, São Paulo, v. 12, n. 3, p. 125-150, jul./set. 2013. 